\title{
Antifilarial activity of diterpenoids from Taxodium distichum
}

Vikas Kushwaha $^{1 \dagger}$, Kirti Saxena ${ }^{1 \dagger}$, Richa Verma ${ }^{1}$, Shiv K. Verma ${ }^{1,4}$, Deepali Katoch², Neeraj Kumar ${ }^{2}$, Brij Lal ${ }^{3}$, P. Kalpana Murthy ${ }^{1^{*}}$ and Bikram Singh ${ }^{2^{*}}$

\begin{abstract}
Background: Lymphatic filariasis caused by Wuchereria bancrofti, Brugia malayi and B. timori, is a debilitating disease with an adverse social and economic impact. The infection remains unabated in spite of treatment with existing antifilarial drugs diethylcarbamazine (DEC) and ivermectin which are chiefly microfilaricides. There is therefore, need for macrofilaricides, embryostatic agents and better microfilaricides. In the present study we explored the antifilarial potential of crude extract and its molecular fractions of the plant Taxodium distichum using in vitro assay systems and rodent models of $B$. malayi infection.
\end{abstract}

Methods: Ethanolic extract (A001) of aerial parts of T. distichum was solvent fractionated and sub-fractionated. Four molecules, 3-Acetoxylabda-8(20), 13-diene-15-oic acid (K001), Beta-sitosterol (K002), labda-8(20),13-diene-15-oic acid (K003) and Metasequoic acid A (KO04) were isolated from the fractions and their structure determined by spectroscopic analysis. The extract, subfractions and molecules were evaluated for antifilarial activity against $B$. malayi by 3-(4,5-dimethylthiazol-2-yl)-2,5 diphenyltetrazolium bromide (MTT) reduction and motility assays in vitro and in two animal models, Meriones unguiculatus and Mastomys coucha, harbouring B. malayi infection.

Results: A001 was effective in killing microfilariae ( $\mathrm{mf}$ ) and adult worms in vitro. The diterpenoid K003 produced $100 \%$ reduction in motility of both $\mathrm{mf}$ and adult worms and $>80 \%$ inhibition in MTT reduction potential of adult female worms. In B. malayi-M. unguiculatus model, A001 killed all the adult worms in $>80 \%$ of infected animals. K003 was embryostatic (> $95 \%$ ) in this model. In the B. malayi-M. coucha model, K003 killed $\sim 54 \%$ of adult worms (macrofilaricidal activity) and rendered $>36 \%$ female worms sterile; it also stopped any further rise in microfilaraemia after day 42 post-initiation of treatment.

Conclusion: Ethanolic extract of aerial parts of the plant $T$. distichum possesses potent antifilarial activity and the active principle was localised to K003 which showed significant macrofilaricidal activity and late suppression of peripheral microfilaraemia and some embryostatic activity. These findings indicate that labdane diterpenoid molecule(s) may provide valuable leads for design and development of new macrofilaricidal agent(s). To the best of our knowledge, this is the first report on antifilarial efficacy of products from the plant $T$. distichum.

Keywords: Taxodium distichum, Brugia malayi, Labdane diterpenoids, In vitro assays, Macrofilaricide, Embryostatic, Mastomys coucha, Meriones unguiculatus, Diethylcarbamazine, Ivermectin

\footnotetext{
*Correspondence: drpkmurthy@yahoo.com; drpkmurthy@gmail.com; psr_murthy@yahoo.com; bikramsingh@ihbt.res.in; bikram_npp@rediffmail. com

${ }^{\dagger}$ Equal contributors

'Division of Parasitology, CSIR-Central Drug Research Institute, New Campus, BS 10/1, Sector 10, Jankipuram Extension, Lucknow 226 031, India ${ }^{2}$ Natural Product Chemistry and Process Development Division, CSIR-Institute of Himalayan Bioresource Technology, Palampur 176 061, HP, India Full list of author information is available at the end of the article
} 


\section{Background}

Lymphatic filariasis (LF), caused by the nematode parasites Wuchereria bancrofti, Brugia malayi and B. timori, is one of the neglected tropical diseases and is recognised as the world's most disabling and disfiguring parasitic disease with an adverse social and economic impact. Around 1.4 billion people in 73 countries worldwide which includes 553 million in India alone, are at risk of the infection $[1,2]$.

The adult parasites live in the lymphatics and lymph nodes and produce millions of juvenile worms called microfilariae $(\mathrm{mf})$ which remain in the pulmonary vessels during the day and appear in the peripheral blood at night (nocturnal periodicity). On entering mosquitoes (vector) during blood meal, the mf undergo two moults in the vector and develop into 3rd stage infective larvae (L3). The L3 enter human host during the vector's blood meal and develop into adult worms after two more moults.

Current methods of controlling the transmission of the infection include administration of the microfilaricides diethylcarbamazine (DEC) and ivermectin either alone or in combination with an anthelmintic albendazole en masse to people living in areas endemic to the infection. This Mass Drug Administration (MDA) strategy raised hopes for elimination of this disease, but unfortunately, the infection is unabated due to the technical limitations of MDA strategy [3]. Besides, the adverse effects of these antifilarials, the lack of adulticidal activity in these drugs to complement their microfilaricidal activity for a two-pronged attack on the parasite and the fast emerging drug resistance to ivermectin are compounding the situation [4]. Therefore, there is a clear need to develop new antifilarial agent(s) that possess not only microfilaricidal activity but, most importantly, also macrofilaricidal activity and if possible, adult worm sterilising activity as well. In this direction our laboratories have been systematically screening a large number of plants to identify biologically active molecules against lymphatic filarial parasite [5-11].

Taxodium distichum (L.) Rich is an ornamental tree commonly known as Bald cypress because of its deciduous character which is unusual in conifers. It is a slow growing and long lived tree [12]. The plant is native to Mississippi valley north to southern Illinois and the coastal plain from Delaware to Mexico [13]. In India, $T$. distichum tree grows in Himachal Pradesh, Uttarakhand and West Bengal. A literature and patent search show that the plant is rich in monoterpenes, diterpenes, sesquiterpenes, flavonoids and their glycosides [14], and there are reports that the plant products show antiviral [14], cytotoxic [15], antitumor [16], anti-oxidant [17], anti-bacterial [17] and antifungal [18] activities. The present study was aimed at determining whether the plant products have any antifilarial activity. To this end, the aerial parts of the plant were selected for investigation. The ethanolic extract, its fractions, sub-fractions and molecules isolated from them were assayed for antifilarial activity using human lymphatic filarial parasite, $B$. malayi in vitro and in animal models of the infection.

\section{Methods}

Plant material, extraction, fractionation and isolation of molecules and their structure elucidation

Aerial parts of the plant $T$. distichum were collected in February, 2010 from Palampur (located at $32.12^{\circ} \mathrm{N}$, $76.53^{\circ} \mathrm{E}$, elevation $1220 \mathrm{~m}$ above sea level), Himachal Pradesh, India, by Dr. Brij Lal (Biodiversity department of CSIR-Institute of Himalayan Bioresource Technology, Palampur, India). The collection was made in one season only. A specimen has been deposited in the herbarium (voucher no. 1200) of CSIR-Institute of Himalayan Bioresource Technology, Palampur.

Air-dried aerial parts of $T$. distichum (1 kg) were ground to a coarse powder and extracted with ethanol $(2000 \mathrm{ml} \times 3)$ in a percolator for $24 \mathrm{~h}$. The combined ethanol extract was concentrated in a rotavapor under reduced pressure and lyophilised to get dried extract (60.2 g, A001). The extract was suspended in water and partitioned successively with n-hexane, chloroform and n-butanol $(3 \times 150 \mathrm{ml})$ three times each and the fraction left was the aqueous fraction. Each fraction thus obtained was concentrated in a rotavapor under reduced pressure and lyophilised to yield four different fractions designated as F001 (6 g), F002 (3 g), F003 (30 g) and F004 (20 g). All fractions were assayed in vitro for antifilarial activity for selecting the most potent one for further fractionation.

Fraction F001 (n-hexane) which was found most effective was subjected to column chromatography over silica gel $(100 \mathrm{~g}, 60-120$ mesh, $90 \times 6 \mathrm{~cm})$ with gradient of ethyl acetate and $n$-hexane $(0.5: 10 ; 0.7: 10 ; 1.25: 10$; $1.5: 10 ; 1.75: 10 ; 2.0: 10 ; 2.25: 10 ; 2.5: 10 ; 3.0: 10 ; 3.5: 10$; $4.0: 10 ; 5.0: 10 ;$ and 7.0:10; v/v). Different fractions of $50 \mathrm{ml}$ volume collected by thin layer chromatography (TLC) monitoring were pooled to six subfractions (SF1SF6). Compound K001 was isolated after direct crystallisation from SF-4. Further, the subfractions were tested for antifilarial activity. As SF-2 was found to show micro- and macrofilaricidal activity it was subjected to column chromatography separation over silica gel 60120 mesh (Merck India Ltd.) and eluted with $7 \%$ ethyl acetate in $n$-hexane and fourteen fractions were collected. Compound K002 was isolated by direct crystallisation. Compounds $\mathrm{K} 003$ and K004 were purified after repeated column chromatography over RP-18 silica (Merck India Ltd.) using $90 \%$ methanol in water. The flowchart (Fig. 1) shows extraction, fractionation and 


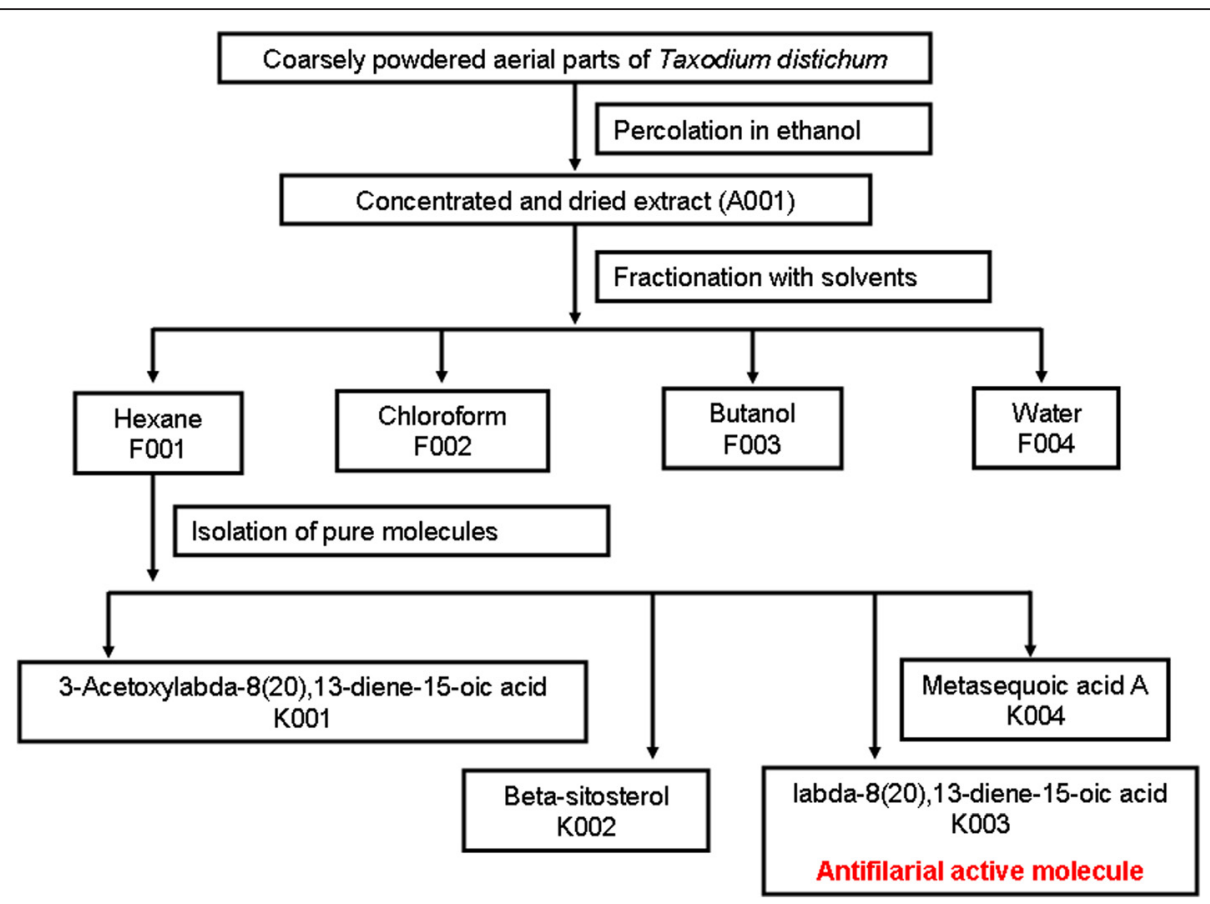

Fig. 1 Flowchart of extraction, fractionation and isolation of pure molecules from Taxodium distichum

isolation of molecules. TLC picture of the isolated pure molecules along with the extract was developed on RP$18 \mathrm{~F}_{254} \mathrm{~S}$ TLC plate (Merck India Ltd.) using solvent system Methanol:Water (3:0.05) (Fig. 2). The structures of the isolated compounds were elucidated using $1 \mathrm{D}, 2 \mathrm{D}$ Nuclear Magnetic Resonance (NMR) using Bruker Avance-300 spectrometer, and by mass spectroscopy using Q-TOF mass spectrometer equipped with an ESI source (Micromass, Manchester, UK). The spectroscopic data was compared with the known data available in literature.

\section{Animals, infection and isolation of parasites}

Two rodent species, the southern multimammate mouse Mastomys coucha and the jird Meriones unguiculatus were obtained from National Laboratory Animal Centre, CSIR-CDRI, Lucknow and used in the present study, these two species are known to be susceptible to $B$. malayi infection. All experiments were conducted in compliance with the Institutional Animal Ethics Committee (IAEC) guidelines for use and handling of the animals (IAEC approval number: IAEC/2010/141). Throughout the study, the animals were housed in climate $\left(23 \pm 2{ }^{\circ} \mathrm{C}\right.$; RH: $\left.60 \%\right)$ and photoperiod (12 h lightdark cycles) controlled animal quarters. They were fed standard rodent "maintenance diet" prepared in-house (QC analysis: carbohydrates $58.30 \%$, protein $21.10 \%$, fat $7.20 \%$, crude fibre $6.60 \%$, moisture $6.80 \%$ ) supplemented with dried shrimps (for M. coucha) and had free access to drinking water. Following the guidelines of
IAEC, the animals were necropsied using sodium pentothal.

Sub-periodic strain of B. malayi was cyclically maintained in $M$. coucha and M. unguiculatus through laboratory bred black-eyed filaria susceptible strain of mosquitoes Aedes aegypti. Each animal was inoculated with 100 (M. coucha) or 200 (M. unguiculatus) L3 isolated from experimentally infected $A$. aegypti, through subcutaneous (s.c.) and intraperitoneal (i.p.) routes, respectively $[19,20]$.

Microfilariae and adult worms were harvested from p.c. of the M. unguiculatus harbouring approximately 56 month-old $B$. malayi infection. The parasites were washed thoroughly with HBSS ( $\mathrm{pH}$ 7.2) containing antibiotics (penicillin: $100 \mathrm{U} / \mathrm{ml}$; streptomycin: $100 \mu \mathrm{g} / \mathrm{ml}$ ) and used for the present study.

\section{Evaluation of antifilarial efficacy in vitro}

Motility and 3-(4,5-dimethylthiazol-2-yl)-2,5 diphenyltetrazolium bromide (MTT; Sigma-Aldrich, USA) reduction assays that indicate viability of the parasites were used [21, 22]. Test samples and ivermectin (purity $95 \%$; Sigma-Aldrich, USA) were dissolved in dimethyl sulfoxide (DMSO; Sigma-Aldrich, USA); the final concentration of DMSO in the incubation medium Hanks Balanced Salt Solution (HBSS; Sigma-Aldrich, USA) containing $100 \mathrm{U} / \mathrm{ml}$ penicillin and $100 \mu \mathrm{g} / \mathrm{ml}$ streptomycin (Sigma-Aldrich, USA), was kept $\leq 0.1 \%$. Diethylcarbamazine-citrate (DEC-C; purity $100 \%$; Sigma-Aldrich, USA) solution was prepared in sterile 


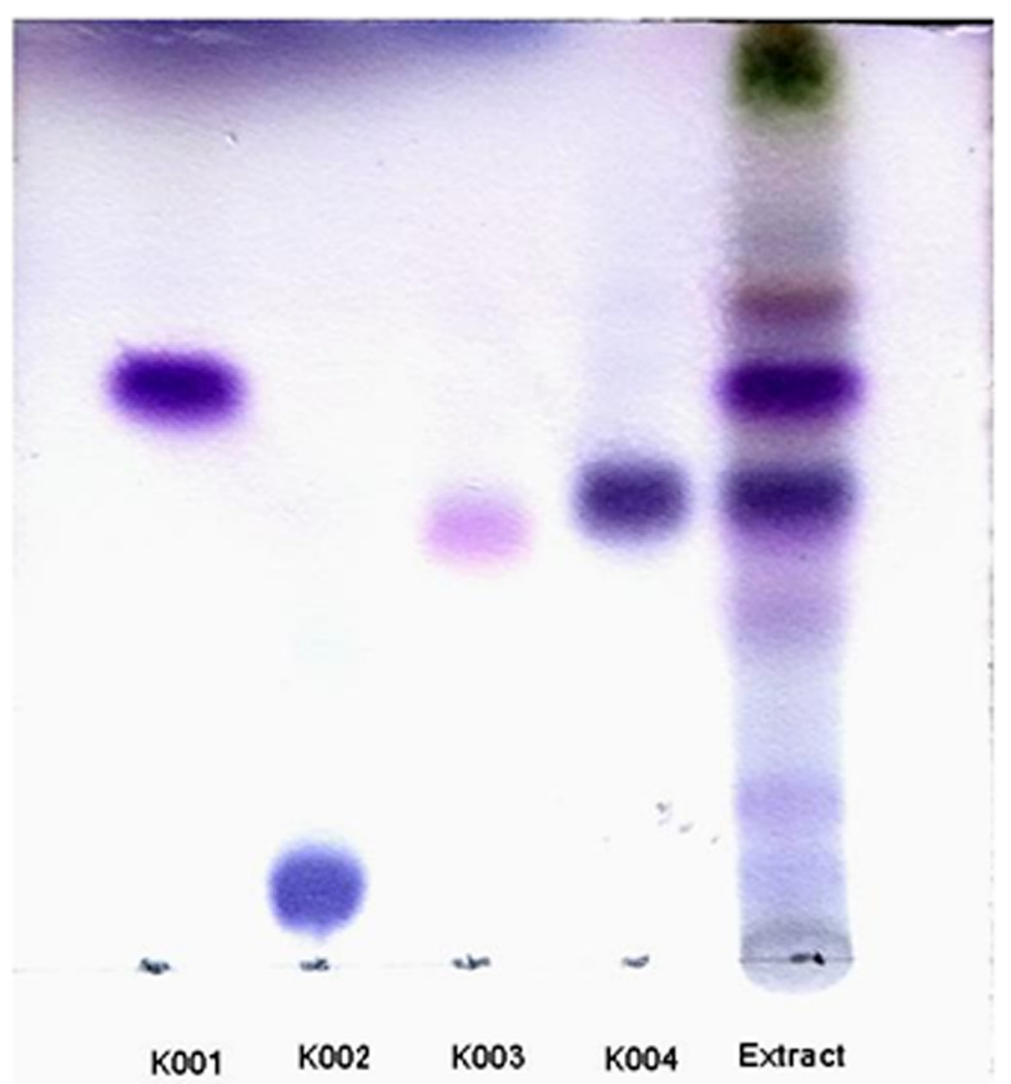

Fig. 2 Thin layer chromatography (TLC) of extract and compounds isolated from Taxodium distichum

distilled water. HBSS containing DMSO $(\leq 0.1 \%)$ alone was used as negative control.

The concentrations of the test agents used were: $500 \mu \mathrm{g} / \mathrm{ml}$ (A001 or its fractions/ subfractions: F001F004/SF1-SF6), $125 \mu \mathrm{g} / \mathrm{ml}$ (isolated compounds/ molecules: K001-K004), $1000 \mu \mathrm{M}$ (DEC) and 10/20 $\mu \mathrm{M}$ (ivermectin). In vitro efficacy of the test agents and reference drugs was assessed on $\mathrm{mf}(40-50 \mathrm{mf} / 100 \mu \mathrm{l} /$ well $)$ in a 96-well cell culture plate (Nunc, Denmark) and on adult female worms (1 worm/ml/well) in a 48-well plate (Nunc, Denmark). The assays were run in triplicates.

Motility assay using $\mathrm{mf}$ and adult worms was carried out as described elsewhere [21-23]. Changes in parasite motility was assessed under a microscope and scored as: $0=$ dead $(100 \%) ; 1-4=$ loss of motility $(1=75 \% ; 2=$ $50 \% ; 3=25 \%$; and $4=$ no loss of motility). The experiment was repeated twice.

MTT-reduction assay was carried out using adult worms as described elsewhere [22]. The viability of the treated worms was assessed by calculating per cent inhibition in MTT-reduction potential of the treated worms over DMSO treated control parasites [22]. A hundred percent inhibition in motility of female parasites or $\mathrm{mf}$ and or $\geq 50 \%$ inhibition in MTT-reduction potential of the treated female parasites were considered to indicate positive antifilarial activity [22].

\section{Determination of $\mathrm{IC}_{50}$ and $\mathrm{CC}_{50}$}

$\mathrm{IC}_{50}$ and $\mathrm{CC}_{50}$ of the test agents were determined using the method described elsewhere $[9,23]$. For $\mathrm{IC}_{50}$, parasite life-cycle stages were incubated with two-fold serial dilutions of the agents (test agents: $7.82-500 \mu \mathrm{g} / \mathrm{ml}$; DEC-C: $15.63-1000 \mu \mathrm{M}$; ivermectin: $0.31-20 \mu \mathrm{M})$ in motility and MTT-reduction assays, using triplicate wells of culture plate. The experiments were repeated twice.

In the $\mathrm{CC}_{50}$ assay, VERO Cell line $\mathrm{C} 1008$ (African green monkey kidney cells) obtained from NLAC, CSIRCDRI, Lucknow, was incubated with three fold serial dilutions of the test agents and reference drugs (starting from $>20$ times conc. of $\mathrm{LC}_{100}$ of the agents). The assay was run in replicates in each of the two independent experiments.

Data were transferred to a graphic program (MS Excel) and $\mathrm{IC}_{50}$ and $\mathrm{CC}_{50}$ were calculated by linear interpolation between the two concentrations above and below $50 \%$ inhibition [24].

Selectivity Index (SI) of the agents was computed by the formula as: $\mathrm{SI}=\mathrm{CC}_{50} / \mathrm{IC}_{50}$. 
All the in vitro tests were repeated twice and Table 1 shows the average values.

\section{Evaluation of antifilarial efficacy in vivo}

Meriones unguiculatus bearing intraperitoneally instilled adult worms and $M$. coucha inoculated with B. malayi L3 and showing microfilaremia in peritoneal cavity on day 3 post adult worm transplantation (p.a.t.) and progressive rise in microfilaraemia in peripheral circulation from day 120-180 post larval inoculation (p.l.i.), were employed as primary and secondary screening models, respectively, for assaying the antifilarial efficacy of the test agents.

The test agents were pulverised to fine powder and suspended in $1 \%$ gum acacia/0.1\% Tween-80 in sterile distilled water. DEC-C and ivermectin were prepared in distilled water and $\leq 0.1 \%$ Tween-80, respectively. The suspensions/solutions of the agents were prepared daily before administration to the animals.

In the M. unguiculatis model, the ethanolic extract (A001) was administered at $500 \mathrm{mg} / \mathrm{kg}$, orally. Compounds $\mathrm{K} 003$ and $\mathrm{K} 004$ were given at $100 \mathrm{mg} / \mathrm{kg}$ body weight, subcutaneously (s.c.). The reference drugs DEC-C and ivermectin were administered to $M$. unguiculatus at 25 and $1 \mathrm{mg} / \mathrm{kg}$ body weight, respectively, while the $M$. coucha model received DEC-C at $50 \mathrm{mg} / \mathrm{kg}$, body weight. The treatment was given for 5 consecutive days starting from day 1 to 5 through oral (A001) or s.c. (rest of the test compounds and reference drugs) routes. Infected animals treated with vehicle only were used as control.

Male M. unguiculatus 8-10 weeks old (40-45 g) transplanted intraperitoneally with freshly isolated adult worms from B. malayi-infected $M$. unguiculatus were used for primary screening of test agents [22]. On day 3 p.a.t., the peritoneal fluid was aspirated and checked for the presence of $\mathrm{mf}$. The treatment was started on day $7 /$ 8 p.a.t. and continued for 5 consecutive days. On day 7/ 8 post-initiation of treatment (p.i.t) and thereafter at fortnightly intervals, the peritoneal fluid was examined under microscope to assess the condition of mf. All animals were killed on day 56 p.i.t. and parasites were collected from p.c., counted and examined for their viability and motility under microscope [10].

Mastomys coucha harbouring 5-7 month-old (L3 induced) $B$. malay infection and showing progressive rise in microfilaraemia was used as secondary screening model [23]. Mf count was recorded in peripheral blood (10 $\mu \mathrm{l}$ tail blood) just before initiation of the treatment (day 0 ), on day $7 / 8$ and thereafter at weekly intervals till day 91 p.i.t. The animals were killed on day 91 p.i.t.

Table 1 In vitro activity of Taxodium distichum and the reference drugs ivermectin and diethylcarbamazine (DEC) on adult worms (AW) and microfilariae (Mf) of Brugia malayi assessed by motility assay (MA) and MTT reduction assay

\begin{tabular}{|c|c|c|c|c|c|c|c|c|}
\hline Antifilarial agent & $\begin{array}{l}\mathrm{LC}_{100}^{\mathrm{a}}(\mu \mathrm{g} / \mathrm{ml}) \\
\text { for } \mathrm{AW} \text { in MA }\end{array}$ & $\begin{array}{l}I C_{50}^{b}(\mu \mathrm{g} / \mathrm{ml}) \\
\text { for } A W \text { in } M A\end{array}$ & $\begin{array}{l}\text { Mean \% inhibition in } \\
\text { MTT reduction by AW }\end{array}$ & $\begin{array}{l}\mathrm{LC}_{100}(\mu \mathrm{g} / \mathrm{ml}) \\
\text { for } \mathrm{Mf} \text { in } \mathrm{MA}\end{array}$ & $\begin{array}{l}I_{50}(\mu \mathrm{g} / \mathrm{ml}) \\
\text { for Mf in MA }\end{array}$ & $\begin{array}{l}\mathrm{CC}_{50}^{c} \\
(\mu \mathrm{g} / \mathrm{ml})\end{array}$ & SI for AW in MA & $\overline{S l}$ for $M f$ in $M A$ \\
\hline A001 (crude extract) & 15.63 & 10.00 & 47.00 & 3.91 & 1.95 & 250 & 25 & 128.29 \\
\hline F001 & 31.25 & 9.84 & 79.63 & 7.83 & 4.92 & 210 & 21.34 & 42.68 \\
\hline F002 & $>125$ & - & 17.00 & $>125$ & 88 & - & - & - \\
\hline F003 & $>125$ & - & 38.00 & $>125$ & 88 & - & - & - \\
\hline F004 & $>125$ & - & 42.00 & $>125$ & 88 & - & - & - \\
\hline SF1 & 31.25 & 12.40 & 46.23 & 7.82 & $<3.95$ & 250 & 20.16 & $>63.29$ \\
\hline SF2 & 7.82 & 5.52 & 78.08 & 7.82 & $<3.95$ & 430 & 77.89 & $>108.86$ \\
\hline SF3 & $>250$ & - & 45.03 & 250.00 & 95 & 340 & - & 3.78 \\
\hline SF4 & 125.00 & 74.33 & 83.86 & 62.50 & 22.10 & 330 & 4 & 14.93 \\
\hline SF5 & $>250$ & - & 43.31 & 125 & - & - & - & - \\
\hline SF6 & $>250$ & - & 32.89 & 250 & - & - & - & - \\
\hline K001 & 62.50 & 41.23 & 76.89 & 250 & 88.38 & 697 & 16.91 & 7.88 \\
\hline K002 & $>250$ & $>250$ & 38.05 & $>250$ & $>250$ & - & - & - \\
\hline K003 & 125 & 74.33 & 82.05 & 31.25 & 18.58 & 180 & 2.42 & 9.69 \\
\hline K004 & 125 & 52.56 & 85.02 & 31.25 & 11.05 & 190 & 3.61 & 17.19 \\
\hline Ivermectin $(\mu \mathrm{M})$ & 5 & 3.05 & 5.80 & 2.5 & 1.57 & 250 & 81.96 & 159.23 \\
\hline DEC-C ( $\mu \mathrm{M})$ & 1000 & 314.98 & 62.54 & 500 & 297.30 & 9000 & 28.57 & 30.27 \\
\hline
\end{tabular}

${ }^{\mathrm{a}} \mathrm{LC} \mathrm{C}_{100}=100 \%$ reduction in motility indicates death of parasite

${ }^{\mathrm{b}} \mathrm{C}_{50}=$ concentration of the agent at which $50 \%$ inhibition in motility of the parasites is achieved

${ }^{\mathrm{C}} \mathrm{CC}_{50}=$ concentration at which $50 \%$ of cells are killed

Abbreviations: SI Selectivity Index $\left(C_{50} / C_{50}\right), D E C-C$ Diethylcarbamazine-citrate

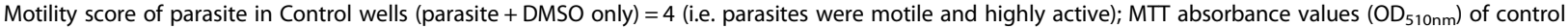
wells (parasites + DMSO only) $=0.64$ 
As a standard practice (following an accepted protocol) all the M. unguiculatus and M. coucha treated with test agents and vehicle were observed daily for their general health and behaviour (cage side observations) throughout the course of treatment and thereafter till termination of the experiment.

Microfilaricidal efficacy of the test agents was evaluated at each time point p.i.t and expressed as percent change in $\mathrm{mf}$ count over the pretreatment level [6].

Macrofilaricidal/adulticidal efficacy of the agents was assessed by calculating percent reduction in adult worm recovery in treated animals over untreated animals [6]. Embryostatic/embryotoxic effect of agents was assessed by examining the uterine contents of female worms using the method described elsewhere [6] and the percent of sterilised worms was determined from total female worms recovered from the treated and control animals [6].

\section{Statistical analysis}

Statistical analyses were carried out using GraphPad Prism 3.0 software. Results were expressed as the mean \pm standard deviation (S.D.) of data obtained from 4-6 animals in two experiments. The data were analysed by Student's ' $t$ ' test and one-way ANOVA followed by Tukey's multiple comparison test, as appropriate. Differences with $P<0.05$ were considered significant. The microfilaricidal efficacy of antifilarials was determined by comparing the slopes of control, K003 and DEC treated groups. The slopes of the regression line were compared by standard procedure.

\section{Results}

\section{Structure elucidation of isolated molecules}

The structures of the characterised molecules are given in Fig. 3.

Compound 1 K001 (3-Acetoxylabda-8(20),13-diene15-oic acid: purity: > $95 \%$ ): white needles, molecular formula $\mathrm{C}_{22} \mathrm{H}_{34} \mathrm{O}_{3} .{ }^{1} \mathrm{H}$ NMR $\left(300 \mathrm{MHz}, \mathrm{CDCl}_{3}\right)$ : $\delta 1.7-$ 1.8, 1.2-1.3 (H-1), 1.4-1.8 (H-2), $4.5(\mathrm{H}-3), 1.2(\mathrm{H}-5), 1.3-$ 1.4 (H-6), 2.3-2.4, 2.0 (H-7), 1.5 (H-9), 1.6-1.8 (H-11), 2.2-2.4, 2.0 (H-12), 5.67 (H-14), 2.17 (H-16), 4.88, 4.53 (H-17), 0.88 (H-18), 0.85 (H-19), $0.72(\mathrm{H}-20), 2.06$ $\left(\mathrm{CH}_{3} \mathrm{CO}\right)$ and ${ }^{13} \mathrm{C}$ NMR $\left(75 \mathrm{MHz}, \overline{\mathrm{CDCl}}_{3}\right): 37.1(\mathrm{C}-1)$, 24.6 (C-2), 81.0 (C-3), 38.4 (C-4), 55.0 (C-5), 24.1 (C-6), 38.3 (C-7), 147.7 (C-8), 56.1 (C-9), 39.6 (C-10), 22.0 (C11), 40.3 (C-12), 163.9 (C-13), 115.4 (C-14), 172.4 (C15), 19.6 (C-16), 107.3 (C-17), 28.6 (C-18), 16.9 (C-19), $\left.14.9(\mathrm{C}-20), 21.6 \underline{(\mathrm{CH}}_{3} \mathrm{CO}\right), 171.3\left(\mathrm{CH}_{3} \underline{\mathrm{CO}}\right) .[\mathrm{M}+\mathrm{H}-$ $\left[\mathrm{H}_{2} \mathrm{O}\right]^{+} 345.5847$.

Compound 2 K002 (Beta-sitosterol, purity: > $97 \%$ ): white needles, molecular formula $\mathrm{C}_{29} \mathrm{H}_{50} \mathrm{O} .{ }^{1} \mathrm{H}$ NMR (300 MHz, $\left.\mathrm{CDCl}_{3}\right): \delta 1.8,1.9(\mathrm{H}-1), 1.4,1.9(\mathrm{H}-2), 3.5$ (H-3), 2.3 (H-4), 5.35, 5.37 (H-6), 2.0, $1.85(\mathrm{H}-7), 1.5,2.0$ (H-8), $0.94(\mathrm{H}-9), 1.5(\mathrm{H}-11), 2.0-2.1(\mathrm{H}-12), 1.05(\mathrm{H}-$ 14), 1.25, 1.6 (H-15), 1.8 (H-16), 1.08 (H-17), 0.69 (H-

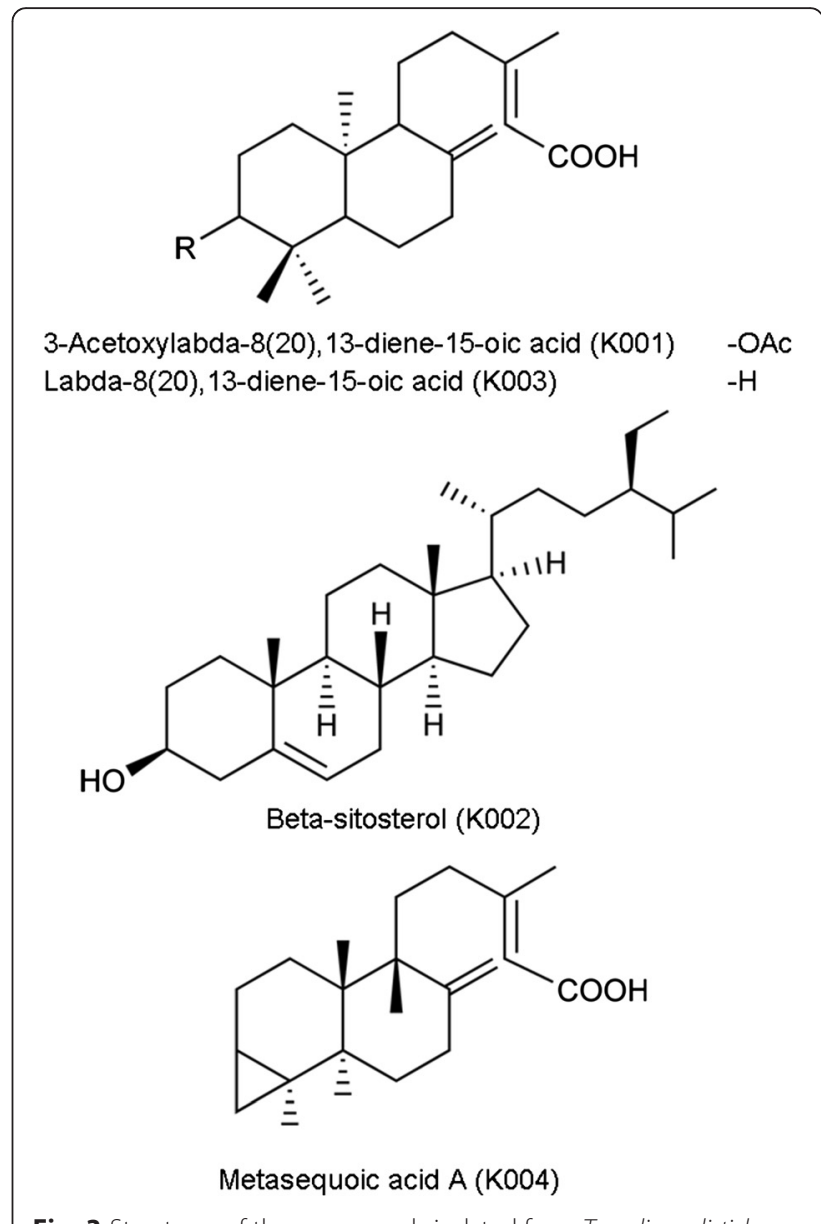

Fig. 3 Structures of the compounds isolated from Taxodium distichum

18), 0.94 (H-19), 1.35 (H-20), 0.85 (H-21), 1.3 (H-22), 1.56 (H-23), 0.9 (H-24), 1.7, 1.3,1.2 (H-25), $1.02(\mathrm{H}-26)$, 1.1 (H-27), $1.2(\mathrm{H}-28), 0.88(\mathrm{H}-29)$ and ${ }^{13} \mathrm{C}$ NMR (75 MHz, $\mathrm{CDCl}_{3}$ ): $37.6(\mathrm{C}-1), 32.3(\mathrm{C}-2), 72.2(\mathrm{C}-3), 42.6$ (C-4), 141.1 (C-5), 122.1 (C-6), 32.0 (C-7), 32.3 (C-8), 50.5 (C-9), 36.9 (C-10), 21.4 (C-11), 40.1 (C-12), 42.6 (C13), 56.4 (C-14), 23.4 (C-15), 28.6 (C-16), 57.1 (C-17), 12.2 (C-18), 19.1 (C-19), 36.5 (C-20), 19.4 (C-21), 34.3 (C-22), 24.7 (C-23), 46.2 (C-24), 29.5 (C-25), 19.8 (C-26), 20.2 (C-27), 26.4 (C-28), 12.3 (C-29). [M+ H] ${ }^{+} 414.3418$.

Compound 3 K003 (labda-8(20),13-diene-15-oic acid: purity: > $95 \%$ ): Pale yellow oil, molecular formula $\mathrm{C}_{20} \mathrm{H}_{32} \mathrm{O}_{2} .{ }^{1} \mathrm{H}$ NMR $\left(300 \mathrm{MHz}, \mathrm{C}_{6} \mathrm{D}_{6}\right): \delta 1.4,1.1(\mathrm{H}-1)$, 1.5-1.6 (H-2), 1.1, $1.2(\mathrm{H}-3), 0.9(\mathrm{H}-5), 1.4,1.6(\mathrm{H}-6)$, 1.9-2.3 (H-7), $1.4(\mathrm{H}-9), 1.3-1.6(\mathrm{H}-11), 1.5-2.4,2.0(\mathrm{H}-$ 12), $5.86(\mathrm{H}-14), 2.2(\mathrm{H}-16), 4.85,4.45(\mathrm{H}-17), 0.82(\mathrm{H}-$ 18), 0.77 (H-19), $0.63(\mathrm{H}-20)$ and ${ }^{13} \mathrm{C}$ NMR $(75 \mathrm{MHz}$, $\left.\mathrm{C}_{6} \mathrm{D}_{6}\right): 38.7(\mathrm{C}-1), \overline{19.8}(\mathrm{C}-2), 42.5(\mathrm{C}-3), 33.8(\mathrm{C}-4), 55.7$ (C-5), 24.8 (C-6), 39.2 (C-7), 148.3 (C-8), 56.6 (C-9), 40.0 (C-10), 21.9 (C-11), 40.4 (C-12), 164.1 (C-13), 115.6 (C14), 173.1 (C-15), 19.4 (C-16), 106.9 (C-17), 33.8 (C-18), 22.0 (C-19), 14.7 (C-20). $[\mathrm{M}+\mathrm{H}]^{+} 305.2917$. 
Compound 4 K004 (Metasequoic acid A: purity: > 95 \%): Pale yellow oil, molecular formula $\mathrm{C}_{20} \mathrm{H}_{30} \mathrm{O}_{2} \cdot{ }^{1} \mathrm{H}$ NMR (300 MHz, CDCl $)$ : $\delta 1.55(\mathrm{H}-1), 1.6(\mathrm{H}-2), 0.45$ (H-3), 1.50-1.51 (H-5), 1.3, 1.9 (H-6), 2.0-2.4 (H-7), 1.531.54 (H-9), 0.8 (H-11), 2.0-2.4 (H-12), 5.68 (H-14), 2.17 (H-16), 4.89, 4.54 (H-17), 1.02 (H-18), 0.66 (H-19), 0.51 $(\mathrm{H}-20)$ and ${ }^{13} \mathrm{C}$ NMR $\left(75 \mathrm{MHz}, \mathrm{CDCl}_{3}\right): 35.0(\mathrm{C}-1)$, 21.36 (C-2), 18.25 (C-3), 20.03 (C-4), 50.5 (C-5), 26.2 (C6), 38.4 (C-7), 148.7 (C-8), 55.9 (C-9), 39.1 (C-10), 22.1 (C-11), 40.5 (C-12), 164.2 (C-13), 115.3 (C-14), 172.6 (C15), 19.6 (C-16), 107.8 (C-17), 28.6 (C-18), 18.28 (C-19), $13.8(\mathrm{C}-20) .[\mathrm{M}+\mathrm{H}]^{+}$303.2429.

The ${ }^{1} \mathrm{H}$ and ${ }^{13} \mathrm{C}$ NMR values for these compounds were similar to those reported in literature [25-29].

\section{In vitro activity of test agents on $\mathrm{mf}$ and adult worms}

Results of in vitro activity of ethanolic extract (A001) of aerial parts of the plant, its fractions, subfractions and compounds are shown in Table 1. A001 was found to be more effective in killing $\mathrm{mf}\left(\mathrm{LC}_{100}: 3.91 \mu \mathrm{g} / \mathrm{ml}\right)$ than adult worms $\left(\mathrm{LC}_{100}: 15.63 \mu \mathrm{g} / \mathrm{ml}\right)$ and the $\mathrm{IC}_{50}$ values for the respective parasite stages were found to be 1.95 and $10.00 \mu \mathrm{g} / \mathrm{ml}$. A001 exerted $47 \%$ inhibition in MTT-reduction assay over the DMSO control. Of the four fractions F001 was more effective in killing (100 \% killing) $\mathrm{mf}\left(\mathrm{LC}_{100}: 7.83 \mu \mathrm{g} / \mathrm{ml}\right)$ requiring four times lesser concentration than needed for killing adult worms $\left(\mathrm{LC}_{100}: 31.25 \mu \mathrm{g} / \mathrm{ml}\right)$; the fraction exerted $80 \%$ inhibition in MTT reduction potential of the adult parasites. Of the six subfractions, SF2 killed both adult worms and $\mathrm{mf}\left(\mathrm{LC}_{100}: 7.83 \mu \mathrm{g} / \mathrm{ml}\right)$ and exerted $78 \%$ inhibition in MTT-reduction assay. SF1 was also active but it was more microfilaricidal $\left(\mathrm{LC}_{100}: 7.83 \mu \mathrm{g} / \mathrm{ml}\right.$ ) than macrofilaricidal $\left(\mathrm{LC}_{100}: 31.25 \mu \mathrm{g} / \mathrm{ml}\right)$; the $\mathrm{IC}_{50}$ value of both the subfractions, SF1 and SF2 against $\mathrm{mf}$ was $<3.95 \mu \mathrm{g} / \mathrm{ml}$. SF4 was less effective on motility of $\mathrm{mf}\left(\mathrm{LC}_{100}: 62.5 \mu \mathrm{g} / \mathrm{ml}\right)$ and adult worms ( $\left.\mathrm{LC}_{100}: 125 \mu \mathrm{g} / \mathrm{ml}\right)$ but it caused $84 \%$ inhibition in MTT reduction assay. The 2 diterpenoid compounds $\mathrm{K003}$ and $\mathrm{K004}$ isolated from SF2 killed mf ( $\mathrm{LC}_{100}$ : $31.25 \mu \mathrm{g} / \mathrm{ml}$ ) and adult worms ( $\left.\mathrm{LC}_{100}: 125 \mu \mathrm{g} / \mathrm{ml}\right)$; both compounds produced $>80 \%$ inhibition in MTT-reduction assay.

DEC-C required $500 \mu \mathrm{M}(\mathrm{mf})$ to $1000 \mu \mathrm{M}$ (adult worms) to kill the parasite stages whereas ivermectin required much lower concentrations to kill both the parasite stages $\left(\mathrm{LC}_{100}\right.$ for $\mathrm{mf}$ and adult worms were $2.5 \mu \mathrm{M}$ and $5 \mu \mathrm{M}$, respectively).

In summary, compounds K003 and K004 of A001 were effective in killing $\mathrm{mf}$ and adult worms in vitro.

\section{In vivo activity of antifilarials: B. malayi-M. unguiculatus model}

Table 2 shows antifilarial efficacy of A001 and compounds $\mathrm{K} 003$ and K004 in B. malayi-M. unguiculatus model (primary screening model). A001 (500 mg/kg, orally) exhibited remarkable adulticidal activity; five of the six treated animals showed $100 \%$ macrofilaricidal ( $q$ $=16.43, P<0.001)$ activity while the sixth animal showed motile and active adult parasites and $28.57 \%$ of the female parasites showed non-viable $\mathrm{mf}$ or dead/distorted embryonic stages in uterus. One-way ANOVA and Tukey's multiple comparison tests showed that compound $\mathrm{K} 003(100 \mathrm{mg} / \mathrm{kg})$ exerted remarkable embryostatic activity $\left(>95 \% ; F_{(4,20)}=88.56, P<0.001\right.$; Table 2; Fig. 4a) as compared to K004, ivermectin, DEC and vehicle treated animals (Table 2). At $100 \mathrm{mg} / \mathrm{kg}$ dose, both the purified compounds produced $>25 \%$ macrofilaricidal activity (K003: 27 \%; K004: $32.20 \%$; Table 2). However, K003 and K004 treated animals showed motile and active $\mathrm{mf}$ in the p.c. and this was not much different from the status of $\mathrm{mf}$ in p.c. of the control animals (data not shown) indicating that the compounds were ineffective against $\mathrm{mf}$ in the $M$. unguiculatus model.

The reference drug ivermectin did not affect $\mathrm{mf}$ in p.c. (data not shown) but produced mild but not statistically significant effect on adult worms. The drug also produced significant embryostatic effect (44\%; $t=18.92, P$ $<0.01$; Table 2) and one-way ANOVA followed by Tukey's multiple comparison test revealed that the embryostatic effect produced by ivermectin was significantly greater $\left(F_{(1,8)}=358.04, P<0.01\right.$; Table 2$)$ than that seen in DEC/K004 treated or untreated animals.

In the M. unguiculatus model, DEC did not affect $\mathrm{mf}$ count or female reproductive potential but exerted mild macrofilaricidal activity (Table 2). Female worms from control M. unguiculatus showed normal and healthy uterine contents (Fig. 4b). Cage-side observations did not reveal any abnormalities in the general health and behavior of $M$. unguiculatus of any group at any time point of observation period. In summary, in the $M$. unguiculatus model A001 killed all the adult worms in > $80 \%$ of infected animals and K003 exhibited >95\% embryostatic activity.

\section{In vivo activity of antifilarials: Brugia malayi-M. coucha model}

Antifilarial efficacy of $\mathrm{K003}$ and reference drug DEC in $B$. malayi-M. coucha system (secondary screening model) is presented in Fig. 5. K003 treatment had more or less no effect on microfilaraemia till day 42 p.i.t., but thereafter microfilaraemia stopped increasing as compared to control (Fig. 5a) (i.e. there was no statistically significant rise in microfilaraemia after day 42 p.i.t) and by day 80 p.i.t, the $\mathrm{mf}$ levels were significantly lower than those in untreated control $(t=4.82, P=0.0004)$ and equaled the levels in DEC treated group $(t=0.062, P=$ 0.9516). The trend in post-treatment microfilaraemia (Fig. 5a) was ascertained by simple regression equation analysis (Table 3) which showed that all the lines have 
Table 2 Antifilarial activity of crude extract of aerial parts of Taxodium distichum, its molecules, and the reference drugs ivermectin and DEC against Brugia malayi in jirds, Meriones unguiculatus (mean \pm standard deviation)

\begin{tabular}{|c|c|c|c|c|c|}
\hline \multirow[t]{2}{*}{ Antifilarial agent } & \multirow{2}{*}{$\begin{array}{l}\text { Dose } \mathrm{mg} / \mathrm{kg} \\
\text { s.c. } \times 5 \text { days }(n)\end{array}$} & \multicolumn{3}{|c|}{ Worms recovered } & \multirow[t]{2}{*}{ Sterilised female worm count (\%) } \\
\hline & & Male & Female & Total (\% reduction over untreated) & \\
\hline \multirow[t]{2}{*}{ A001 (Crude extract) } & 500 p.o. (6) & 0 & 0 & $0^{* * *}(5)$ & $-2(28.57)$ \\
\hline & & & & $11.00(1)^{b}$ & \\
\hline \multirow[t]{2}{*}{ K003 } & $100(5)$ & $0.40 \pm 0.89$ & $8.00 \pm 0.71$ & $8.40 \pm 1.14$ & $8.00 \pm 0.71$ \\
\hline & & & & $(27.12)$ & $(>95)^{* * *}$ \\
\hline \multirow[t]{2}{*}{ K004 } & $100(5)$ & 0 & $8.00 \pm 0.82$ & $8.00 \pm 0.82$ & $1.50 \pm 0.58$ \\
\hline & & & & $(32.20)$ & $(18.85 \pm 7.22)$ \\
\hline \multirow[t]{2}{*}{ Ivermectin ${ }^{a}$} & $1(4)$ & $2.75 \pm 0.96$ & $6.25 \pm 1.50$ & $9.67 \pm 2.52$ & $2.75 \pm 0.96$ \\
\hline & & & & $(22.43)$ & $(44.29 \pm 5.15)^{* *}$ \\
\hline \multirow[t]{2}{*}{ DEC-C $C^{a}$} & $25(6)$ & $2.60 \pm 0.55$ & $6.60 \pm 1.14$ & $9.20 \pm 1.48$ & $0.60 \pm 0.89$ \\
\hline & & & & (22.03) & $(7.86 \pm 11.41)$ \\
\hline \multirow[t]{2}{*}{ Control (Vehicle treated) } & $-(5)$ & $3.40 \pm 1.97$ & $8.40 \pm 2.07$ & $11.80 \pm 0.45$ & $0.40 \pm 0.55$ \\
\hline & & & & & $(5.71 \pm 7.82)$ \\
\hline
\end{tabular}

${ }^{a}$ Reference drugs; DEC-C: Diethylcarbamazine-Citrate

${ }^{b}$ One animal showed presence of live adult worms but not dead/calcified worms

${ }^{* *} P<0.01$ (ivermectin vs Control/DEC/K004); ${ }^{* *} P<0.001$ (K003 vs control/K004/ivermectin/DEC; A001 vs control/K003/K004/ivermectin/DEC)

significant slopes and the rate of change of microfilaraemia between any two treatment groups (i.e, control vs K003, control vs DEC, and DEC vs K003) was statistically significant. K003 also exerted $53.94 \%$ macrofilaricidal $(q=7.557, P<0.001$; Fig. $5 b)$ activity compared to untreated control animals; recovery of female parasites from the treated animals was lower than that of control animals $(q=10.20, P<0.0001)$. More than $36 \%$ of the surviving female parasites were found sterile although this was not statistically significant $(P>0.05)$ when compared with the sterile female parasites of control animals ( $q=0.87, P=0.913)$. Further, one-way ANOVA analysis revealed that $\mathrm{K} 003$ was superior to DEC with respect to macrofilaricidal efficacy as evidenced by lesser worm recovery from K003 treated animals $(q=4.08, P=0.041)$.
DEC-C $(50 \mathrm{mg} / \mathrm{kg})$ which is chiefly a microfilaricide, caused $>80 \%$ reduction in microfilarial count on day $7 /$ 8 p.i.t. which gradually increased and relapsed by day 49 p.i.t.; the count further increased rapidly and crossed the pretreatment level by day 56 p.i.t. (Fig. 5a). DEC also showed around $26.47 \%$ macrofilaricidal and $20 \%$ female sterilising activity but this activity was not statistically significant compared to control (Fig. 5b); however, significantly lower numbers of male parasites were recovered from DEC treated animals $(q=7.28, P=00074)$ than from the control animals.

Microfilaraemia in control animals was progressively higher than the pretreatment level and never equalled the 0 day level. About $28 \%$ of female worms recovered from the control animals were found to be sterilised.

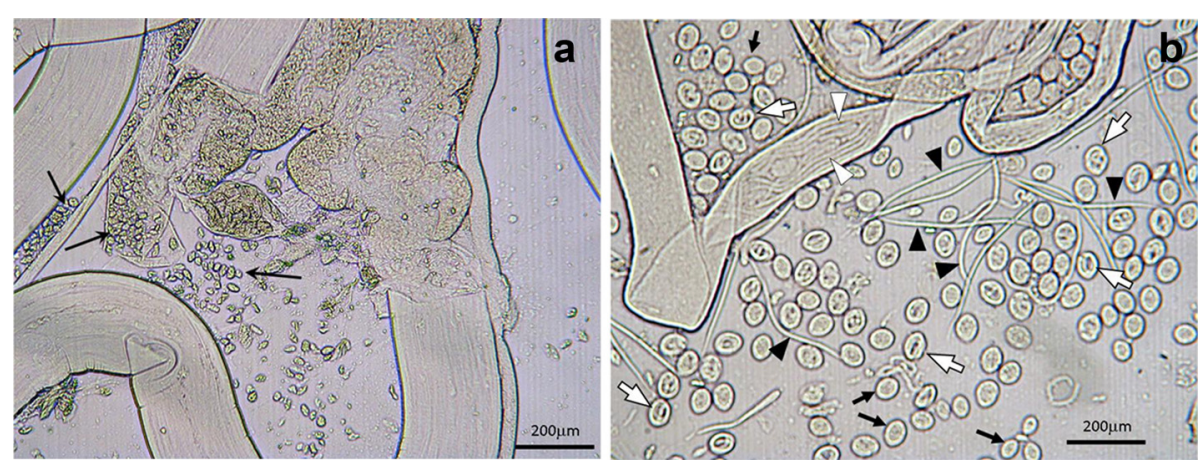

Fig. 4 Embryostatic effect of compound K003 of Taxodium distichum in female parasites of Brugia malayi in Meriones unguiculatus. a Uterus of female worm contained distorted eggs and the embryos were devoid of developing microfilariae ( $\mathrm{mf}$ ) (arrows). b Female worm from vehicle treated animals (control) showing eggs (arrows), developing $\mathrm{mf}$ in embryos (hollow arrows) and fully developed mf (hollow arrowheads); fully developed $\mathrm{mf}$ expelled from uterus by gentle pressure on the worm during preparation was also seen around the worm (filled arrowheads) 

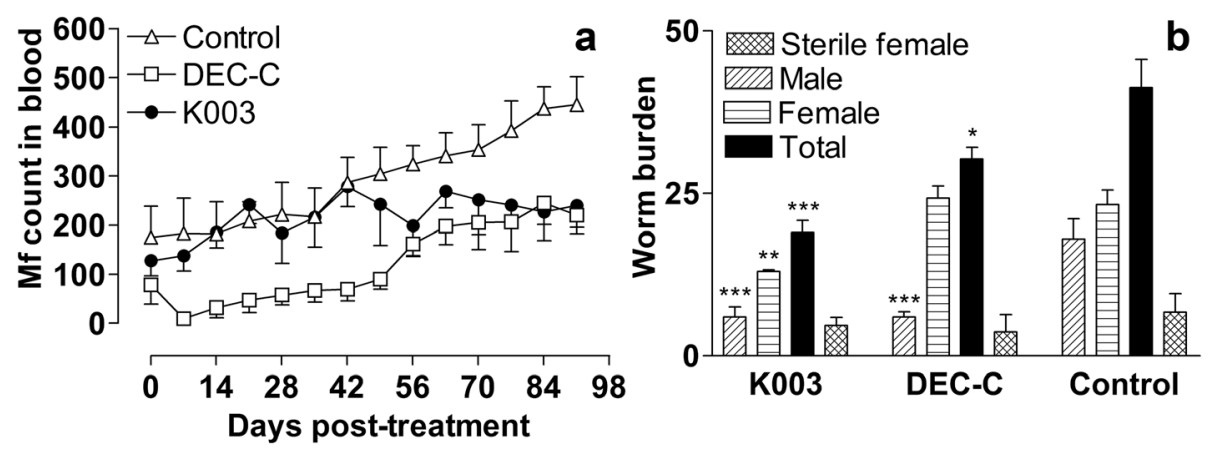

Fig. 5 Antifilarial activity of compound K003 of Taxodium distichum and the reference drug diethylcarbamazine-citrate (DEC-C) against Brugia malayi in Mastomys coucha. Mf count values are mean \pm standard deviation of 4-6 animals in two experiments. a Pre- and post- treatment levels of microfilaraemia in treated and control animals. Statistical significance levels are given in Table 3. b Adult worms and sterile female worms recovered from control, K003 and DEC treated animals

None of the animals showed any signs of toxicity as inferred from cage-side observations of gross clinical signs. In summary, in B. malayi-M. coucha model, K003 produced significant macrofilaricidal activity and rendered more than $36 \%$ female worms sterile; it also stopped any further rise in microfilaraemia after day 42 p.i.t.

\section{Discussion}

In the present bioassay-guided fractionation of the ethanolic extract from the aerial parts of the conifer $T$. distichum, we found that the antifilarial activity was localised to labdane diterpenoids $\mathrm{K003}$ and K004 of the subfractions SF2. Although there are reports that diterpenoids show antibacterial, antifungal, anti-protozoal and antiinflammatory $[30,31]$ activities, there are no previous reports on antifilarial activity of the compounds from the conifer $T$. distichum.

In line with our earlier studies on a number of plant products $[5,9,11]$, the main emphasis of the present study was to identify antifilarial compounds of $T$. distichum that preferentially target the adult worms and embryogenesis in the female worms. This is considered as a superior approach for control of filariasis (WHO recommends this approach for new drug discovery) since killing/interfering with embryogenesis of even one female adult worm will stop production of millions of $\mathrm{mf}$ that

Table 3 Regression equations determining the trends in microfilarial counts in Fig. 5a

\begin{tabular}{lll}
\hline Antifilarial agent & Regression line & $P$-value \\
\hline K003 & $183.65+0.82$ days & 0.04 \\
& $(0.352)$ & \\
DEC-C & $-21.04+2.95$ days & $<0.001$ \\
& $(0.24)$ & \\
Untreated control & $135.44+3.350$ days & $<0.001$ \\
& $(0.170)$ & \\
\hline
\end{tabular}

Values in parentheses represent standard errors of slopes circulate in the blood and this may effectively interrupt or reduce the transmission of the infection. Unfortunately, the currently available antifilarial drugs are largely microfilaricides with little effect, if any, on adult worms.

In the present study, we found micro- and macrofilaricidal activity in the crude extract and purified compounds $\mathrm{K} 003$ and K004 in vitro. However, the $\mathrm{IC}_{50}$ of pure compounds was higher than that of crude extract. At present the reasons for this differences in the activity between ethanolic extract and the compound isolated from it are not clear, but it appears that greater activity in the crude extract could be due to additive or synergistic effects of $\mathrm{KO03}$ and $\mathrm{K004}$ in it; other substance(s) such as flavonoids in the ethanolic extract might have also contributed to this activity since we have recently shown that some flavonoids possess antifilarial activity [22]. In the M. unguiculatus model (primary model), the ethanolic extract (A001) showed a remarkable macrofilaricidal activity while the purified compound K003 of the extract exerted embryostatic activity only with mild macrofilaricidal activity. Conversely, in the M. coucha model (secondary model), the compound exhibited significant macrofilaricidal activity but only mild (statistically not significant) embryostatic activity. However, $M$. coucha model exhibits close similarity to human infection in several respects such as the course of infection [19], pathogenesis of disease manifestations [32, 33], immune responses [34] and responses to antifilarials [35-38]. The differences in the response of the two rodent models to the same compound are apparently due to differences in the way they metabolise the compound and the resultant variation in the ratio of bioactive metabolites responsible for macrofilaricidal and embryostatic effects.

In the $M$. coucha model, microfilaraemia stopped increasing after day 42 p.i.t. with $\mathrm{K} 003$, and by day 80 p.i.t., the levels were significantly lower than those in 
untreated control and equaled the levels in DEC treated group. Summing it up, the overall microfilaraemia was the highest in control group and the least in DEC group with K003 taking the intermediate position (Fig. 5a). The reasons for lesser changes in microfilaraemia in K003treated group are not clear at present. But it appears that late suppression of peripheral microfilaraemia in M. coucha is due to the adult worm mortality and the inhibitory effect on embryogenesis produced by K003. As the adult worm mortality was higher in males than in females, this may have lead to lower mating rate and consequent irregular $\mathrm{mf}$ production. With respect to the standard reference drugs, both DEC and ivermectin were ineffective against $\mathrm{mf}$ in $M$. unguiculatus model but DEC showed strong microfilaricidal effect in M. coucha [9-11, 35-37, 39, 40]. This is in agreement with the known microfilaricidal efficacy of DEC in M. coucha, cats [41] and humans [42-44]. Similar differences between B. malayi-M. unguiculatus and B. malayi-M. coucha systems with respect to antifilarial activity of DEC and ivermectin have been reported by several investigators $[6,36-38]$. In a similar vein, DEC showed mild adulticidal and embryostatic activities in the M. coucha model and poor adulticidal activity in the M. unguiculatus model. In the M. unguiculatus model, K003 and ivermectin showed strong and moderate embryostatic effect, respectively, while DEC was ineffective.

The mechanism by which the labdane diterpenoid compounds $\mathrm{K} 003$ and $\mathrm{K} 004$ of $T$. distichum exerted filaricidal activity in vitro and in vivo remains to be investigated. Several possible mechanisms may be considered including an indirect action via the known antibacterial activity of diterpenoids of this plant. The antibacterial activity might have resulted in killing of the filarial symbionts Wolbachia spp. which supports the survival of the parasite [45].

\section{Conclusions}

Ethanolic extract A001 prepared from aerial parts of the plant $T$. distichum was solvent fractionated, subfractionated and four molecules: 3-Acetoxylabda-8(20), 13diene-15-oic acid (K001), Beta-sitosterol (K002), labda8(20),13-diene-15-oic acid (K003) and Metasequoic acid A (K004) were isolated. The structures of the compounds were elucidated by spectroscopic analysis. A001 and labdane diterpenoid compounds K003 and K004 showed micro- and macrofilaricidal activity in vitro. In the M. unguiculatus model, A001 killed all the adult worms in $>80 \%$ of infected animals; the active principle was localised to labdane diterpenoid compound K003 which showed remarkable embryostatic activity in this model. In M. coucha model the compound K003 exerted significant macrofilaricidal activity with late suppression of peripheral microfilaraemia and some embryostatic activity. Thus, in conclusion the findings indicate that labdane diterpenoid molecule(s) may provide valuable lead for design and development of new macrofilaricidal agent(s). Future studies will include chemical modification of K003 and K004 to maximise the antifilarial activity; regulatory toxicity studies will be carried out on the molecules maximised for activity.

\begin{abstract}
Acknowledgements
The authors thank the Directors of CSIR-CDRI, Lucknow, U.P. and CSIR-IHBT, Palampur, H.P. India, for their keen interest and encouragement during the present investigation. The authors thank Dr. P.S.R. Murthy for critical review of the manuscript. This study was supported in part by the Network projects SPLENDID and NWP 0037 of Council of Scientific and Industrial Research, New Delhi, India. Statistical analysis was carried out by Dr. Mukesh Srivastava, Clinical and Experimental Medicine, Biometry section, CSIR-CDRI, Lucknow. VK and KS are thankful to Indian Council of Medical Research, New Delhi, for the award of Senior Research Fellowship. DK is thankful to Department of Science and Technology, New Delhi, India, for the award of Women Scientist Fellow. This manuscript bears communication numbers CSIR-CDRI: 9233 and CSIR-IHBT: 3551
\end{abstract}

\section{Authors' contributions}

Conceived and designed the experiments: PKM, BS. Performed the experiment: VK, KS, RV, SKV, DK, NK. Analysed the data: PKM. Contributed reagents/materials/analysis tools: PKM, BS. Wrote the paper: PKM, BS, DK. BL identified and collected the plant material and prepared its herbarium. All authors approved the final version of the manuscript.

\section{Competing interests}

The authors declare that they have no competing interests.

\section{Author details}

'Division of Parasitology, CSIR-Central Drug Research Institute, New Campus, BS 10/1, Sector 10, Jankipuram Extension, Lucknow 226 031, India. ${ }^{2}$ Natural Product Chemistry and Process Development Division, CSIR-Institute of Himalayan Bioresource Technology, Palampur 176 061, HP, India. ${ }^{3}$ Biodiversity Division, CSIR-Institute of Himalayan Bioresource Technology, Palampur 176 061, HP, India. ${ }^{4}$ Present Address: USDA, ARS, APDL, BARC-East Bldg 1001, 10300 Baltimore Avenue, Beltsville, MD 20705, USA.

Received: 27 October 2015 Accepted: 13 May 2016

Published online: 31 May 2016

References

1. Rebollo MP, Bockarie MJ. Toward the elimination of lymphatic filariasis by 2020: treatment updates and impact assessment for the endgame. Expert Rev Anti Infect Ther. 2013;11:723-31.

2. WHO. Sixth meeting of the technical advisory group on the global elimination of lymphatic filariasis, Geneva, Switzerland, 20-23 September 2005. Wkly Epidemiol Rec. 2005;80:401-8.

3. Burkot TR, Durrheim DN, Melrose WD, Speare R, Ichimori K. The argument for integrating vector control with multiple drug administration campaigns to ensure elimination of lymphatic filariasis. Filaria J. 2006;5:1-7.

4. Singh BK, Mishra M, Saxena N, Yadav GP, Maulik PR, Sahoo MK, Gaur RL, Murthy PK, Tripathi RP. Synthesis of 2-sulfanyl-6-methyl-1,4dihydropyrimidines as a new class of antifilarial agents. Eur J Med Chem. 2008;43:2717-23.

5. Chatterjee RK, Fatma N, Murthy PK, Sinha P, Kulshrestha DK, Dhawan BN. Macrofilaricidal activity of the stembark of Streblus asper and its major active constituents. Drug Dev Res. 1992;26:67-8.

6. Gaur R, Sahoo M, Dixit S, Fatma N, Rastogi S, Kulshreshtha D, Chatterjee RK, Murthy PK. Antifilarial activity of Caesalpinia bonducella against experimental filarial infections. Indian J Med Res. 2008;128:65-70.

7. Mathew N, Misra-Bhattacharya S, Perumal V, Muthuswamy K. Antifilarial lead molecules isolated from Trachyspermum ammi. Molecules. 2008;13:2156-68.

8. Saxena K, Dube V, Gupta V, Lakshmi M, Mishra S, Gupta S, Arora A, Lakshmi $V$, Sharma RK, Jain GK, et al. Antifilarial efficacy of Hibiscus sabdariffa on lymphatic filarial parasite Brugia malayi. Med Chem Res. 2011;20:1594-602. 
9. Kalani K, Kushwaha V, Verma R, Murthy PK, Srivastava SK. Glycyrrhetinic acid and its analogs: a new class of antifilarial agents. Bioorg Med Chem Lett. 2013;23:2566-70

10. Yadav D, Kushwaha V, Saxena K, Verma R, Murthy PK, Gupta MM. Diarylheptanoid compounds from Alnus nepalensis express in vitro and in vivo antifilarial activity. Acta Trop. 2013;128:509-17.

11. Yadav D, Singh SC, Verma RK, Saxena K, Verma R, Murthy PK, Gupta MM. Antifilarial diarylheptanoids from Alnus nepalensis leaves growing in high altitude areas of Uttarakhand, India. Phytomedicine. 2013;20:124-32.

12. Brown CA, Montz GN. Baldcypress: The Tree Unique, the Wood Eternal. Baton Rouge: Claitor's Publishing Division; 1986.

13. Little EL. Atlas of United States Trees: Conifers and Important Hardwoods, vol. 1. Washington D.C: USDA Forest Service; 1971.

14. Ibrahim NA, Gengaihiand SEL, Nazif NM. Chemical composition and biological activity of Taxodium distichum L. Rich leaves growing in Egypt. JASMR. 2006;1:53.

15. Abou Dahab MA, El-Bahr MK, Taha HS, Habib AM, Bekheet SA, Gabr AM, Refaat A. Cytotoxic activity of Taxodium calli extracts on rat liver cells. J Appl Sci Res. 2007;3:1987-96.

16. Kupchan SM, Karim A, Marcks C. Tumor inhibitors. 48. Taxodione and taxodone, two novel diterpenoid quinone methide tumor inhibitors from Taxodium distichum. J Org Chem. 1969;34:3912-8.

17. Tantawy ME, Sakhawy FS, Dohly MA, Ross SA. Chemical composition and biological activity of the essential oil of the fruit of Taxodium distichum $\mathrm{L}$. Rich growing in Egypt. J Essent Oil Res. 1999;11:386-92.

18. Kusumoto N, Ashitani T, Murayama T, Ogiyama K, Takahashi K. Antifungal abietane-type diterpenes from the cones of Taxodium distichum Rich. J Chem Ecol. 2010;36:1381-6.

19. Murthy PK, Tyagi K, Roy Chowdhury TK, Sen AB. Susceptibility of Mastomys natalensis (GRA strain) to a subperiodic strain of human Brugia malayi. Indian J Med Res. 1983;77:623-30.

20. Murthy PK, Murthy PS, Tyagi K, Chatterjee RK. Fate of infective larvae of Brugia malayi in the peritoneal cavity of Mastomys natalensis and Meriones unguiculatus. Folia Parasitol. 1997;44:302-4.

21. Murthy PK, Chatterjee RK. Evaluation of two in vitro test systems employing Brugia malayi parasite for screening of potential antifilarials. Curr Sci. 1999; 77:1084-9.

22. Lakshmi V, Joseph SK, Srivastava S, Verma SK, Sahoo MK, Dube V, Mishra SK, Murthy PK. Antifilarial activity in vitro and in vivo of some flavonoids tested against Brugia malayi. Acta Trop. 2010;116:127-33.

23. Murthy PK, Joseph SK, Murthy PS. Plant products in the treatment and control of filariasis and other helminth infections and assay systems for antifilarial/anthelmintic activity. Planta Med. 2011;77:647-61.

24. Huber W, Koella JC. A comparison of three methods of estimating EC50 in studies of drug resistance of malaria parasites. Acta Trop. 1993;55:257-61.

25. Braun S, Breitenbach H. Strukturaufklärung einer neuen diterpensäure aus Metasequoia glyptostroboides mit hilfe der 13C-NMR-spektroskopie. Tetrahedron. 1977;33:145-50.

26. Lopes LMX, Bolzani VS. Lignans and diterpenes of three Aristolochia species. Phytochemistry. 1988;27:2265-8.

27. Sakan F, Iwashita T, Hamanaka N. Structures of Metasequoic acid A and B. Chem Lett. 1988;1:123-6.

28. Wilson WK, Sumpter RM, Warren JJ, Rogers PS, Ruan B, Schroepfer Jr GJ. Analysis of unsaturated C27 sterols by nuclear magnetic resonance spectroscopy. J Lipid Res. 1996;37:1529-55.

29. Habib MR, Nikkon F, Rahman M, Haque ME, Karim MR. Isolation of stigmasterol and beta-sitosterol from methanolic extract of root bark of Calotropis gigantea (L.). Pak J Biol Sci. 2007;10:4174-6.

30. Demetzos C, Dimas KS. Labdane-type diterpenes: Chemistry and biological activity. Stud Nat Prod Chem. 2001;25:235-92.

31. Bero J, Fre'de'rich M, Quetin-Leclercq J. Antimalarial compounds isolated from plants used in traditional medicine. J Pharm Pharmacol. 2009:61:1401-33.

32. Murthy PK, Joseph SK, Abbas M, Murthy PSR. Pathobiology of lymphatic filariasis: Understanding at molecular level. Proc Nat Acad Sci India. 2009;79: 177-94

33. Murthy P, Srivastava A, Joshi A, Sen A, Murthy P, Ghatak S. Physiopathological changes during infection in multimammate rats. I: Histological studies. IRCS Med Sci. 1986;14:1106-7.
34. Tyagi K, Murthy P, Sen A. Sequential changes in the antibody response of Mastomys natalensis consequent to Brugia malayi infection. Indian J Med Res. 1985;81:269-74.

35. Tyagi K, Murthy PK, Chatterjee RK, Sen AB. Chemotherapeutic response of Brugia malayi to antifilarials in Mastomys natalensis. Indian J Parasitol. 1986; 10:195-207.

36. Schares G, Hofmann B, Zahner H. Antifilarial activity of macrocyclic lactones: comparative studies with ivermectin, doramectin, milbemycin A4 oxime, and moxidectin in Litomosoides carinii, Acanthocheilonema viteae, Brugia malayi, and B. pahangi infection of Mastomys coucha. Trop Med Parasitol. 1994:45:97-106

37. Sashidhara KV, Kumar A, Rao KB, Kushwaha V, Saxena K, Murthy PK. In vitro and in vivo antifilarial activity evaluation of 3,6-epoxy [1,5]dioxocines: a new class of antifilarial agents. Bioorg Med Chem Lett. 2012;22:1527-32.

38. Sashidhara KV, Rao KB, Kushwaha V, Modukuri RK, Verma R, Murthy PK. Synthesis and antifilarial activity of chalcone-thiazole derivatives against a human lymphatic filarial parasite, Brugia malayi. Eur J Med Chem. 2014;81: 473-80.

39. Tanaka H, Takaoka M, Matsuda H, Hayashi Y. Effect of diethylcarbamazine on microfilariae of Brugia malayi in the jird, Meriones unguiculatus. Jpn J Exp Med. 1981;51:195-6.

40. Tripathi R, Tiwari V, Misra-Bhattacharya S, Tyagi K, Srivastava V, Murthy P. 7O- [4-methyl piperazine-1- (2-acetyl)]- 2H-1-benzopyran-2-one: A novel antifilarial lead compound. Acta Trop. 2003;87:215-24.

41. Edeson JF, Laing AB. Studies on filariasis in Malaya: the effect of diethylcarbamazine on Brugia malayi and B. pahangi in domestic cats. Ann Trop Med Parasitol. 1959;53:394-9.

42. Wilson T. Hetrazan in the treatment of filariasis due to Wuchereria malayi. Trans R Soc Trop Med Hyg. 1951;44:643-66.

43. Turner L. Studies on filariasis in Malaya: treatment of Wuchereria malayi filariasis with diethylcarbamazine in single daily doses. Trans R Soc Trop Med Hyg. 1959;53:180-8.

44. Chen T. Demontration of macrofilaricidal action of hetrazan, antimony and arsenic preparation in man. Chin Med J. 1964;83:625-40.

45. Hoerauf A. New strategies to combat filariasis. Expert Rev Anti Infect Ther. 2006:4:211-22.

\section{Submit your next manuscript to BioMed Central and we will help you at every step:}

- We accept pre-submission inquiries

- Our selector tool helps you to find the most relevant journal

- We provide round the clock customer support

- Convenient online submission

- Thorough peer review

- Inclusion in PubMed and all major indexing services

- Maximum visibility for your research

Submit your manuscript at www.biomedcentral.com/submit 